\title{
Occurrence and Distribution of Polycyclic Aromatic Hydrocarbons in Water and Sediment Collected along the Harbour Line, Mumbai, India
}

\author{
V. Dhananjayan, ${ }^{1}$ S. Muralidharan, ${ }^{2}$ and Vinny R. Peter ${ }^{2}$ \\ ${ }^{1}$ Industrial Hygiene and Toxicology Division, Regional Occupational Health Centre (Southern), ICMR, Kannamangala PO, \\ Bangalore 562 110, India \\ ${ }^{2}$ Division of Ecotoxicology, Sálim Ali Centre for Ornithology and Natural History, Coimbatore 641 108, India
}

Correspondence should be addressed to V. Dhananjayan, dhananjayan_v@yahoo.com

Received 25 April 2012; Accepted 8 October 2012

Academic Editor: Xosé A. Álvarez-Salgado

Copyright ( 2012 V. Dhananjayan et al. This is an open access article distributed under the Creative Commons Attribution License, which permits unrestricted use, distribution, and reproduction in any medium, provided the original work is properly cited.

\begin{abstract}
This study investigated the occurrence of polycyclic aromatic hydrocarbons (PAHs) in water and sediment samples collected along the harbour line, Mumbai, India. The $\sum$ PAHs quantified in water and sediment samples were ranged from $8.66 \mathrm{ng} / \mathrm{L}$ to $46.74 \mathrm{ng} / \mathrm{L}$ and from $2608 \mathrm{ng} / \mathrm{g}$ to $134134 \mathrm{ng} / \mathrm{g}$ dry wt., respectively. Significantly high concentration of $\sum$ PAHs was found in water samples of Sewri and sediment samples of Mahul $(P<0.05)$. PAH concentrations detected in the present study were several folds higher than the existing sediment quality criteria suggested by various statutory agencies. The PAH composition patterns in water and sediments suggest the dominance of high molecular weight compounds and indicate important pyrolytic and petrogenic sources. The occurrence of PAHs in the marine environment has attracted the attention of the scientific community as these compounds are frequently detected in seawater and sediments at increasing levels and can have adverse health effects on marine organisms and humans. PAH concentrations detected at Sewri-Mahul site were sufficiently high to pose a risk to marine organisms if they are exposed continuously to this concentration. Hence, continuous monitoring of the ecosystem is highly warranted.
\end{abstract}

\section{Introduction}

All over the world over there have been imminent problems of pollution in many of the coastal regions resulting in significant damage to marine ecosystems. Polycyclic aromatic hydrocarbons (PAHs) are a group of over 100 different chemicals that are formed during the incomplete burning of coal, oil and gas, garbage, and other organic substances $[1,2]$. These contaminants generate considerable interest because some of them are highly carcinogenic in laboratory animals and have been implicated in breast, lung, and colon cancers in humans [3-5]. Accordingly, they are included in the US EPA and the EU priority pollutants list. PAHs can reach surface waters and sediment in different ways, including atmospheric deposition, urban run-off, municipal and industrial effluents, and oil spillage or leakage $[6,7]$. Owing to their low aqueous solubility and strong hydrophobic nature, these contaminants tend to associate with particulate material in the aquatic environment, with the underlying sediments as their ultimate sink [8].

Recent efforts by the EPA have been aimed at establishing sediment quality criteria in an effort to further reduce human exposure to PAH, especially via ingestion of shellfish. Sediments may be a significant source of PAH to the overlying water column particularly in areas where historical PAH input to the sediments has been high. Because some of the PAHs in sediments are not readily available to partition (i.e., $\mathrm{PAH}$ associated with soot) and are therefore not bioavailable [9], measuring the PAH in the overlying water may provide a better indication of exposure of marine organisms to PAH than discrete sediment sampling. Also, the distribution of $\mathrm{PAH}$ in the sediments may be quite heterogeneous and small numbers of samples may not provide a representative distribution, while overlying water measurements can be made much more extensively in a short period of time [10]. 
It has also been emphasized that open seas play a role as a final sink for persistent toxic contaminants and accumulate on marine organisms [11]. The coastal zone represents that part of the land affected by its proximity to the sea and the part of the sea that is affected by its proximity to the land. Papers concerning PAHs in seawater and sediment in India are scarce, due to their very low concentrations in that matrix, in comparison with the concentrations in wastes, sewage, and contaminated soils. Unprecedented increase of human activities and other sources in and around has imposed considerable stress on the surrounding marine environment, and Mumbai harbor is no exception. Mumbai is one of the fastest growing metropolitan cities. Its population is projected to increase from 18.3 million, as per 2001 census, to 22.4 million in 2011. The quality of environment is deteriorating due to release of contaminants from industries and municipal wastes. It was also estimated that $2485 \mathrm{MLD}$ wastes are released in to the marine environment from both industries and domestic sewage [12]. The major objective of the present study was to determine the distribution of PAHs in water and sediment, to assess the toxicological implications of these contaminants, and to generate baseline information on the pollution status along harbour line, Mumbai, India.

\section{Materials and Methods}

2.1. Study Area. Mumbai is one of the major cities in India which is located along the western coast of the country. City with a human population density of 25,000 persons $/ \mathrm{km}^{-2}$ generates $2.2 \times 10^{6} \mathrm{~m}^{3} \mathrm{~d}^{-1}$ of domestic sewage out of which about $2 \times 10^{6} \mathrm{~m}^{3} \mathrm{~d}^{-1}$ enters marine waters including creeks and bays, largely untreated [13]. It has great diversification of industries in metropolitan region. About $8 \%$ of industries in the country are located around Mumbai in the upstream. A variety of industries, including refineries and petrochemical complexes, from this area are releasing their effluents largely untreated into the sea. There are number of ports wherein the ship and cargo handling activities contribute to marine pollution. Sewri-Mahul and Nhava mud flats about 1000 ha have been identified as an important bird area (IBA) [14]. Sewri-Mahul mudflats $\left(19^{\circ} 01^{\prime} 00^{\prime \prime} \mathrm{N}, 72^{\circ} 52^{\prime} 60^{\prime \prime} \mathrm{E}\right.$ ) (Figure 1) which extent over an area of $10 \mathrm{~km}$ long and $3 \mathrm{~km}$ wide are dominated by mangroves all along the coast. The Sewri Bay is situated just off the wide mouth of Thane Creek along the northern periphery of Mumbai's eastern harbour.

2.2. Sample Collection. Seawater samples ( $1 \mathrm{~L}$ volume) for determination of PAH were collected during 2008 along the harbour line (Sewri, Mahul, Nhava), Mumbai, India (Figure 1). A total of 27 (9 sample pooled into 3 samples from each location) water samples were collected at $1 \mathrm{~m}$ depth by submerging a pre-cleaned glass amber bottle by hand. Water was filtered under vacuum through a Whatman $\mathrm{GF} / \mathrm{F}$ filter (previously muffled at $300^{\circ} \mathrm{C}$ overnight). The samples were stored in PTFE bags and frozen at $-20^{\circ} \mathrm{C}$ until processing. Twenty seven sediment $(9$ samples pooled in to 3 from each location) were collected during the

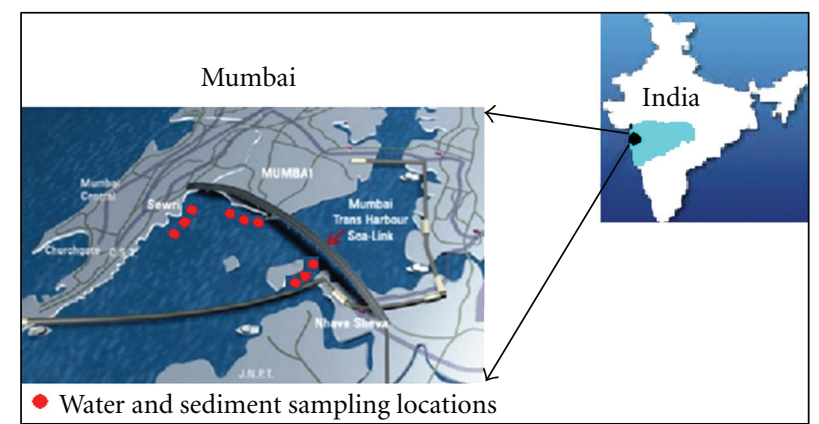

FIGURE 1: Study area showing water and sediment sample collection locations at Mumbai harbor line, Maharashtra, India.

research period. Pre-cleaned PVC core sampler was used for sampling. Sediment surfaces were sliced to $1 \mathrm{~cm}$-thick slices immediately after sampling. The sediment samples were sealed in polythene covers and transported to the laboratory at SACON, Coimbatore, in ice box and stored at $-20^{\circ} \mathrm{C}$ in the deep freezer until analysis.

2.3. Sample Processing. Water samples were extracted with dichloromethane (glass distilled grade; $3 \times 100 \mathrm{~mL}$ ). The first aliquot was used to rinse the sampling bottle and the remaining was used for solvent extraction. The two solvent extracts were combined over anhydrous sodium sulphate (also previously muffled at $300^{\circ} \mathrm{C}$ overnight). The collected extract was transferred to a pre-cleaned "hypovial", capped with a PTFE septum, and stored at $-20^{\circ} \mathrm{C}$ prior to analysis. The extract was allowed to return to room temperature, and then reduced to $2 \mathrm{~mL}$ by means of a rotary evaporator with a water-bath operated at $<30^{\circ} \mathrm{C}$ so as to minimize loss of volatile components. The reduced extract was then transferred to a $10 \mathrm{~mL}$ test-tube and reduced to near dryness under a stream of nitrogen, before being made up to $1 \mathrm{~mL}$ volume by addition of Acetonitrile. Sample extracts were then filtered into an auto sampler vial.

Freeze dried sediment was air dried, ground with pestle and mortar, and sieved through $0.5 \mathrm{~mm}$ sieve prior to further processing. Ten gram of dry sediment mixed with sodium sulfate and copper granules were extracted twice in $100 \mathrm{~mL}$ cyclohexane for $30 \mathrm{~min}$. The extracts were concentrated to $0.5 \mathrm{~mL}$ under a gentle stream of nitrogen. The concentrated extracts were fractionated by a silica gel column $(4 \mathrm{~mm}$ i.d. $90 \mathrm{~mm}$ ). The column was then eluted first with $3.5 \mathrm{~mL}$ of hexane and the solution discarded. Further elution was by benzene $(5 \mathrm{~mL})$ to obtain PAHs [16]. All the extracts were concentrated by gentle $\mathrm{N} 2$ blowdown to about $100 \mu \mathrm{L}$.

2.4. Chemical Analysis. All the samples were quantified for PAHs using HPLC (Agilent 1100) consisting of programmable fluorescence detector at excited and emission wavelength of $260 \mathrm{~nm}$ and $500 \mathrm{~nm}$, respectively. A $20 \mu \mathrm{L}$ aliquot of the extract was injected through an auto sampler into C18 column (Zorbax $4.6 \times 250 \mathrm{~mm}$ ) of $5 \mu \mathrm{m}$ particle size. The temperature of the column was maintained at $20^{\circ} \mathrm{C}$. Water/Acetonitrile (ACN) was used as mobile phase with a 
flow of $1 \mathrm{~mL} / \mathrm{min}$. The initial content of ACN will be $50 \%$ and then increased into 60\% (0-3 min) and 95\% (3-14 $\mathrm{min})$. This level will be held constant for 24 minutes until the end of the analysis. Recoveries of the compounds from fortified samples $(50 \mathrm{ng} / \mathrm{g}$ ) ranged from 94 to $103 \%$ and the results were not corrected for per cent recovery and the results were expressed in wet weight basis. Analyses were run in batches of 10 samples plus four quality controls (QCs) including one reagent blank, one matrix blank, one QC check sample, and one random sample in duplicate. The minimum detection limit for all the compounds analyzed was $10 \mathrm{ng} / \mathrm{g}$.

Statistics. All the data were log transformed to get normal distribution. One way analysis of variance (ANOVA) was performed to assess the variation locations. Means were compared using the Bonferroni multiple comparison test. The significant level was $P<0.05$. All the calculations were done using statistical software, SPSS student version 10 .

\section{Results and Discussion}

This paper presents results from analyses of PAHs in water and sediment samples collected along the harbor line, Mumbai, India. Concentration range of individuals and total PAHs are given in Tables 2 and 3.

3.1. PAH Concentrations in Water. The mean total concentrations of $15 \mathrm{PAHs}$ ( $\sum \mathrm{PAHs}$ ) in water ranged from $8.66 \mu \mathrm{g} / \mathrm{L}$ Nhava to $46.74 \mu \mathrm{g} / \mathrm{L}$ at Sewri (Table 1). The highest concentration $(104.07 \mu \mathrm{g} / \mathrm{L})$ was observed at Sewri, where oil intrusion was clearly visible. Among the three locations, samples collected from Nhava detected lower concentration than other two places (Figure 2). Similarly, high concentration $(66.74 \mu \mathrm{g} / \mathrm{L})$ was also found at Mahul, which is close to sewage outlet from Mumbai. Sewri-Mahul mudflats have a surface area of about $4 \mathrm{sq} \mathrm{km}$. The Mahul rivulet, highly polluted with wastes from Vadala, drains directly into this area. The amount of PAHs detected there is obviously related to urban runoffs, sewage discharges, and intense shipping and oil refinery activities. Ship breaking and oil seepage from industrial activities near Sewri area lead to high concentrations of total PAHs. Additionally, boats and ships transports in these regions were discharging black smokes throughout their movement, hence there are many nonpoint sources in the bay, contributing to the wide variations of PAH concentrations detected.

In terms of individual PAH composition in water, almost all of the compounds (11 out of 15) analyzed were detected at all the sampling places. Many of the samples from Sewri and Mahul were present at concentrations in excess of $\mu \mathrm{g} / \mathrm{L}$, suggesting that the water in the area was heavily contaminated by PAHs. Such a wide range of PAHs at different concentrations indicates that there are potentially many different sources of PAHs in the area, possibly including combustion followed by oil residues, sewage outfalls, and industrial wastewater. From the distribution of PAHs in water alone, it is difficult to differentiate these different sources of input, nevertheless,

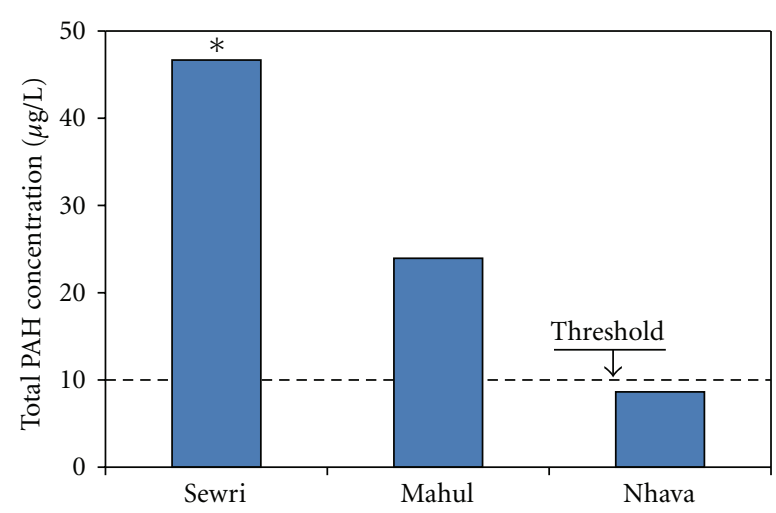

FIgURE 2: Concentration and comparison of PAHs in water sample collected from different locations along harbor line, Mumbai, India. *ANOVA, $P<0.05$.

the data can act as an indication of the potential impacts of such high levels of PAHs on the local ecosystems.

The total PAH concentrations found in water along the harbor line, Mumbai, are several orders of magnitude higher than those detected in various other studies around the world (Table 3). Similarly, comparable high levels of PAHs were also found in seawater samples of Daya Bay, China [18], and northern Spanish [19]. Although PAHs do not show extremely high acute toxicity to aquatic organisms, the lower molecular mass compounds tend to exhibit higher lethal toxicity than the larger PAHs [33]. In addition, lethal concentration (LC50) down to less than $10 \mu \mathrm{g} / \mathrm{L}$ has been reported for various organisms including mysid [34, 35]. The PAH concentrations detected in water samples of Sewri and Mahul clearly show (Figure 2) that the concentrations are greater than $10 \mu \mathrm{g} / \mathrm{L}$, as a result, acute toxicity may have been caused to certain exposed organisms [33]. It should be noted that different numbers of target analytes ( $\mathrm{PAH}$ congeners) and instrument were employed in individuals studies.

\subsection{PAH Concentrations in Sediment. The $\sum \mathrm{PAH}$ con-} centrations in sediment ranged from $17 \mathrm{ng} / \mathrm{g}$ at Sewri to $134134 \mathrm{ng} / \mathrm{g}$ at Mahul with mean concentrations of 2608$51606 \mathrm{ng} / \mathrm{g}$ dry wt. (Table 2). Although the higher load of PAHs was recorded in water samples of Sewri, sediment from Mahul recorded the highest concentrations of PAHs. The highest concentration was observed at Mahul, which is close to sewage intrusion to seashore and also receive water flow from Sewri, which is closer to Mahul. The total PAH concentration detected in sediment samples of Mahul is 20 times higher than the levels detected in Sewri and 13 times higher than those detected in sediment samples of Nhava (Figure 3).

In terms of individual PAH composition in sediment, the most compounds analysed except naphthalene were detected at all the sediment samples. Many of the PAH compounds were present at low concentration range. As far as the composition pattern of PAHs in sediments is concerned, it is mostly dominated by four-ring PAHs as shown in Table 2. 
TABLE 1: Concentrations of $\sum$ PAHs $(\mu \mathrm{g} / \mathrm{L})$ in water collected along the harbour line, Mumbai, India.

\begin{tabular}{|c|c|c|c|c|c|c|}
\hline \multirow{3}{*}{ PAHs } & \multicolumn{6}{|c|}{ Place of collection } \\
\hline & \multicolumn{2}{|c|}{ SEWRI $(n=3)^{*}$} & \multicolumn{2}{|c|}{ MAHUL $(n=3)^{*}$} & \multicolumn{2}{|c|}{ NHAVA $(n=3)^{*}$} \\
\hline & Range & Mean & Range & Mean & Range & Mean \\
\hline Naphthalene & $<1$ & $<1$ & $<1$ & $<1$ & $<1$ & $<1$ \\
\hline Acenaphthene & $<1-2.98$ & 1.33 & $<1-2.13$ & 1.39 & $<1$ & $<1$ \\
\hline Fluorene & $<1-2.55$ & 1.52 & $<1$ & $<1$ & $<1$ & $<1$ \\
\hline Phenanthrene & $<1$ & $<1$ & $<1-3.14$ & 1.08 & $<1$ & $<1$ \\
\hline Anthracene & $<1$ & $<1$ & $<1$ & $<1$ & $<1$ & $<1$ \\
\hline Fluoranthene & $<1-5.11$ & 1.7 & $<1-1.84$ & 1.17 & $<1-3.05$ & 1.02 \\
\hline Pyrene & $<1$ & $<1$ & $<1$ & $<1$ & $<1$ & $<1$ \\
\hline Benzo(a)anthracene & $<1-2.93$ & 1.78 & $<1-3.48$ & 1.18 & $<1-3.16$ & 1.35 \\
\hline Chrysene & $<1$ & $<1$ & $<1$ & $<1$ & $<1$ & $<1$ \\
\hline Benzo(b)fluoranthene & $<1-23.2$ & 8.83 & $<1-17.3$ & 5.61 & $<1-8.05$ & 2.58 \\
\hline Benzo(k)fluoranthene & $<1-2.06$ & 1.29 & $<1-2.75$ & 1.25 & $<1$ & $<1$ \\
\hline Benzo(a)pyrene & $<1-1.94$ & 1.32 & $<1-4.67$ & 1.57 & $<1-2.03$ & 1.34 \\
\hline Dibenzo(a,h)anthracene & $<1-28.2$ & 10.9 & $<1-12.9$ & 4.38 & $<1-1.97$ & 1.04 \\
\hline Benzo(g,h,i)perylene & $<1-15.5$ & 7.97 & $<1-5.53$ & 2.52 & $<1$ & $<1$ \\
\hline Indeno(1,2,3-cd)pyrene & $<1-19.6$ & 10.1 & $<1-13$ & 3.93 & $<1-2.23$ & 1.33 \\
\hline Total PAHs & $<1-104.07$ & 46.74 & $<1-66.74$ & 24.08 & $<1-20.49$ & 8.66 \\
\hline
\end{tabular}

$<1$ : values below detectable concentration, ${ }^{*}$ pooled from 9 water samples.

TABLE 2: Concentrations of $\sum$ PAHs (ng/g, dry wt.) in sediment collected along the harbour line, Mumbai, India.

\begin{tabular}{|c|c|c|c|c|c|c|}
\hline \multirow{3}{*}{ PAHs } & \multicolumn{6}{|c|}{ Place of collection } \\
\hline & \multicolumn{2}{|c|}{ SEWRI $(n=3)^{*}$} & \multicolumn{2}{|c|}{ MAHUL $(n=3)^{*}$} & \multicolumn{2}{|c|}{ NHAVA $(n=3)^{*}$} \\
\hline & Range & Mean & Range & Mean & Range & Mean \\
\hline Naphthalene & $<1$ & $<1$ & $<1$ & $<1$ & $<1$ & $<1$ \\
\hline Acenaphthene & $<1-245$ & 110 & $<1-5265$ & 1821 & $<1$ & $<1$ \\
\hline Fluorene & $<1$ & $<1$ & $<1-28$ & 9 & $<1$ & 16 \\
\hline Phenanthrene & $<1-354$ & 120 & $<1-51$ & 31 & $9-24$ & 410 \\
\hline Anthracene & $<1-331$ & 110 & $<1-6.2$ & 2 & $<1-1228$ & 658 \\
\hline Fluoranthene & $<1$ & $<1$ & $<1-70496$ & 24857 & $527-955$ & 17 \\
\hline Pyrene & $<1-12$ & 8 & $<1-419$ & 271 & $8-23$ & 89 \\
\hline Benzo(a)anthracene & $<1-6$ & 2 & $<1-107$ & 54 & $37-143$ & 152 \\
\hline Chrysene & $<1-22$ & 8 & $<1-344$ & 170 & $13-424$ & 193 \\
\hline Benzo(b)fluoranthene & $<1-2796$ & 932 & $<1$ & $<1$ & $110-470$ & 293 \\
\hline Benzo(k)fluoranthene & $<1-472$ & 204 & $<1-40914$ & 17486 & $<1-480$ & 9 \\
\hline Benzo(a)pyrene & $<1-265$ & 90 & $<1-364$ & 201 & $<1-28$ & 739 \\
\hline Dibenzo(a,h)anthracene & $<1-359$ & 135 & $104-1450$ & 999 & $316-1417$ & 210 \\
\hline Benzo(g,h,i)perylene & $17.3-920$ & 337 & $92-13696$ & 5153 & $<1-491$ & 1251 \\
\hline Indeno $(1,2,3-c d)$ pyrene & $<1-1498$ & 552 & $168-994$ & 552 & $<1-3395$ & $<1$ \\
\hline Total PAHs & $17-7280$ & 2608 & $364-134134$ & 51606 & $1020-9078$ & 4037 \\
\hline
\end{tabular}

$<1$ : values below detectable concentration, ${ }^{*}$ pooled from 9 sediment samples.

Pereira et al. [36] also showed that four-ring PAHs dominated PAH distributions in sediments from San Francisco Bay. Pyrolysis/combustion of fossil materials yield such PAH assemblages, which are subsequently introduced into the marine environment by coastal and river runoff $[37,38]$.
Industrial and domestic wastes are often another important local source. The changes in the composition pattern of PAHs between sampling sites may occur due to variations in additional input sources. The coastal region of Mumbai receives industrial discharges up to 230 million liters per 
TABLE 3: Comparison of total PAH concentrations $(\mu \mathrm{g} / \mathrm{L})$ in sub-surface water from various marine sites around the world.

\begin{tabular}{lcccc}
\hline Location & Year of Sampling & $N$ & Range & References \\
\hline Chesapeake Bay, USA & 1995 & 17 & $0.02-0.0657$ & Gustafson and Dickhut [9] \\
Baltic Sea & 1995 & 14 & $0.300-0.594$ & Maldonado et al. [15] \\
Western Xiamen Bay, China & 1998 & - & $0.106-0.945$ & Zhou et al. [16] \\
Alexandria coast, Egypt & - & - & $0.013-0.120$ & El Nemr and Abd-Allah [17] \\
$\begin{array}{l}\text { Daya Bay, China } \\
\text { Northern Spanish }\end{array}$ & 1999 & 16 & $4.228-29.32$ & Zhou and Maskaoui [18] \\
$\begin{array}{l}\text { Saronikos Gulf (Greece) } \\
\text { Gerlache Inlet sea (Antarctica) }\end{array}$ & - & 25 & $0.19-28.8$ & González et al. [19] \\
$\begin{array}{l}\text { Deep Bay, South China } \\
\text { Western Taiwan Strait, China }\end{array}$ & - & 17 & $0.425-0.459$ & Valavanidis et al. [20] \\
Mumbai Harbour Line, India & 2004 & - & $0.005-0.009$ & Stortini et al. [21] \\
\hline
\end{tabular}

$N$ : number of PAH compounds analysed in each study.

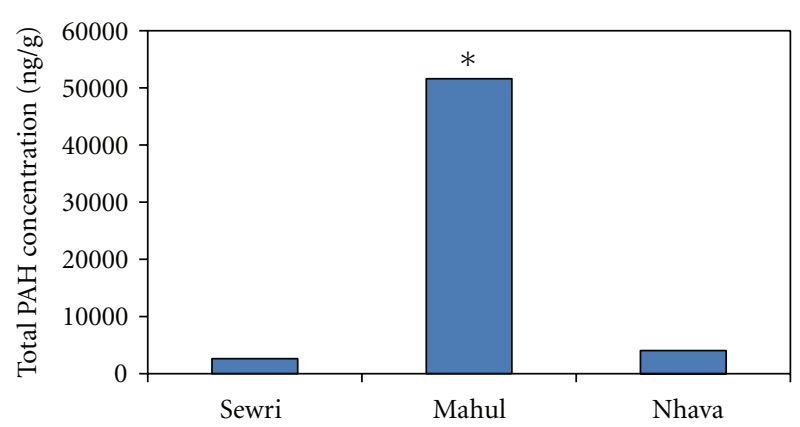

Figure 3: Concentration and comparison of PAHs in sediment sample collected from different locations along harbor line, Mumbai, India. *ANOVA, $P<0.05$.

day (MLD) and domestic wastes of around 2200 MLD of which 1800 MLD are untreated [12]. As a result, the high concentrations of PAHs in sediment could be caused by the large amount of soil runoff and sewage discharged from this area into seawater. The results seem to suggest that PAHs in the area are derived from both the combustion of fossil fuels and petrogenic inputs.

The levels of sediment contamination by PAHs in along the harbor line, Mumbai, India is fivefold lower than the levels reported in sediment of Kitimat Harbour, Canada [25]. The total concentrations of 15PAHs in sediment of present study are several folds higher than that the levels found in Victoria Harbour, Hong Kong [24], Baltic Sea [26], Masan Bay, Korea [27], and other places (Table 4). It is also worth noting that different numbers of parent $\mathrm{PAH}$ compounds were analysed in different studies, and that the compounds measured may be different; so the comparison of total $\mathrm{PAH}$ levels from different studies have to be treated with caution. Additionally, high concentrations of total and carcinogenic PAHs were also reported in fish samples collected from same location [39].
In order to assess whether sediments in Mumbai harbor will cause toxic effects, the PAH levels in sediments were compared against effects-based guideline values such as the effects range-low (ER-L), effects range-median (ERM), and apparent effects threshold values developed by the US National Oceanic and Atmospheric Administration [40]. Among the three study locations, the maximum mean total PAH concentrations $(51606 \mathrm{ng} / \mathrm{g}$ ) were found in sediment samples collected from Mahul followed by Nhava $(4037 \mathrm{ng} / \mathrm{g})$. These levels were significantly higher than the ER-L value (4000 ng/g). The total PAH concentrations found in sediment samples in the present study locations exceeded the maximum values of $2000-4000 \mathrm{ng} / \mathrm{g}$ in sediment quality guidelines proposed by Ontario Ministry of the Environment [41].

\section{Conclusion}

This study provides important data set on PAH levels in the water and sediments along harbor line, Mumbai, India. The levels of PAHs in water and sediment were several folds higher than the other study reports from various countries. The PAH distribution profile indicated potential source dependence, as the levels were generally higher in the vicinity of known inputs such as oil terminals and ports. There are implications for the quality of seafood from many aquaculture areas destined for human consumption. The findings point to the urgent need to establish a monitoring programme for persistent organic pollutants such as PAHs, not only in water and sediment but also in the organisms themselves to ensure that any excess in concentrations over environmental quality standards is rapidly reported and necessary actions are taken. Their presence in marine sediments combined with other potentially toxic compounds can result in negative effects, which have yet to be investigated to any great extent. 
TABLE 4: Comparision of total PAH concentrations (ng/g, dry wt.) in sediment from various marine sites around the world.

\begin{tabular}{|c|c|c|c|c|}
\hline Location & Year of Sampling & $N$ & Range & References \\
\hline Victoria Harbour, Hong Kong, China & 1992 & 8 & $700-26100$ & Hong et al. [24] \\
\hline Kitimat Harbour, Canada & - & 15 & $310-528000$ & Simpson et al. [25] \\
\hline Baltic Sea & 1996 & 18 & $3.96-22100$ & Baumard et al. [26] \\
\hline Masan Bay, Korea & 1998 & 16 & $41.5-1100$ & Khim et al. [27] \\
\hline Western Xiamen Bay, China & 1998 & 16 & $247-480$ & Zhou et al. [16] \\
\hline East China Sea & - & - & $17-157$ & Bouloubassi et al. [28] \\
\hline Bohai Sea and Yellow Sea & - & 10 & $20.4-5734$ & Ma et al. [29] \\
\hline Northern Adriatic Sea & 1996 & 22 & $30-600$ & Notar et al. [30] \\
\hline Daya Bay, China & 1999 & 16 & $115-1134$ & Zhou and Maskaoui [18] \\
\hline Deep Bay, South China & 2004 & 15 & $353.8-128.1$ & Qiu et al. [22] \\
\hline Southwestern Barents Sea & 2006 & 22 & $58.8-326$ & Boitsov et al. [31] \\
\hline Cienfuegos Bay, Cuba & - & - & $180-5500$ & Tolosa et al. [32] \\
\hline Mumbai Harbour Line, India & 2008 & 15 & $17-134134$ & Present study \\
\hline
\end{tabular}

\section{Acknowledgments}

The authors sincerely thank Maharashtra State Road Development Corporation (MSRDC), India, for financial assistance. They are grateful to Drs. V. S. Vijayan, S. N. Prasad, Lalitha Vijayan and R. Jayakumar, SACON, for their support. They appreciate S. Patturajan and Muragesan for their assistance in all their laboratory works.

\section{References}

[1] M. M. Mumtaz, J. D. George, K. W. Gold, W. Cibulas, and C. T. De Rosa, "ATSDR evaluation of health effects of chemicals. IV. Polycyclic aromatic hydrocarbons (PAHs): understanding a complex problem," Toxicology and Industrial Health, vol. 12, no. 6, pp. 742-971, 1996.

[2] T. E. McGrath, J. B. Wooten, C. W. Geoffrey, and M. R. Hajaligol, "Formation of polycyclic aromatic hydrocarbons from tobacco: the link between low temperature residual solid (char) and PAH formation," Food and Chemical Toxicology, vol. 45, no. 6, pp. 1039-1050, 2007.

[3] M. Pufulete, J. Battershill, A. Boobis, and R. Fielder, "Approaches to carcinogenic risk assessment for polycyclic aromatic hydrocarbons: a UK perspective," Regulatory Toxicology and Pharmacology, vol. 40, no. 1, pp. 54-66, 2004.

[4] A. Ramesh, S. A. Walker, D. B. Hood, M. D. Guillén, K. Schneider, and E. H. Weyand, "Bioavailability and risk assessment of orally ingested polycyclic aromatic hydrocarbons," International Journal of Toxicology, vol. 23, no. 5, pp. 301-333, 2004.

[5] K. B. Okona-Mensah, J. Battershill, A. Boobis, and R. Fielder, "An approach to investigating the importance of high potency polycyclic aromatic hydrocarbons (PAHs) in the induction of lung cancer by air pollution," Food and Chemical Toxicology, vol. 43, no. 7, pp. 1103-1116, 2005.

[6] A. Gogou, I. Bouloubassi, and E. G. Stephanou, "Marine organic geochemistry of the Eastern Mediterranean: 1. Aliphatic and polyaromatic hydrocarbons in Cretan Sea surficial sediments," Marine Chemistry, vol. 68, no. 4, pp. 265$282,2000$.
[7] S. G. Wakeham, "Aliphatic and polycyclic aromatic hydrocarbons in Black Sea sediments," Marine Chemistry, vol. 53, no. 3-4, pp. 187-205, 1996.

[8] P. F. Landrum and J. A. Robbins, "Bioavailability of sediment associated contaminants to benthic invertebrates," in Sediments: Chemistry and Toxicity on in-Place Pollutants, R. Baudo, J. P. Giesy, and H. Muntau, Eds., pp. 237-263, Lewis Publishers, 1990.

[9] K. E. Gustafson and R. M. Dickhut, "Distribution of polycyclic aromatic hydrocarbons in Southern Chesapeake Bay surface water: evaluation of three methods for determining freely dissolved water concentrations," Environmental Toxicology and Chemistry, vol. 16, pp. 452-461, 1997.

[10] K. A. Maruya, R. W. Risebrough, and A. J. Horne, "Partitioning of polynuclear aromatic hydrocarbons between sediments from San Francisco Bay and their porewaters," Environmental Science and Technology, vol. 30, no. 10, pp. 2942-2947, 1996.

[11] S. Tanabe, M. S. Prudente, S. Kan-Atireklap, and A. Subramanian, "Mussel watch: marine pollution monitoring of butyltins and organochlorines in coastal waters of Thailand, Philippines and India," Ocean and Coastal Management, vol. 43, no. 8-9, pp. 819-839, 2000.

[12] M. D. Zingde and K. Govindan, "Health status of coastal waters of Mumbai and regions around," in Environmental Problems of Coastal Areas in India, V. K. Sharma, Ed., pp. 119132, Book Well Publishers, New Delhi, India, 2000.

[13] M. D. Zingde, Indian National Science Academy, New Delhi, 1999.

[14] M. Z. Islam and A. R. Rahmani, Indian Bird Conservation Network, Bombay Natural History Society and Bird life International (UK), 2004.

[15] C. Maldonado, J. M. Bayona, and L. Bodineau, "Sources, distribution, and water column processes of aliphatic and polycyclic aromatic hydrocarbons in the northwestern Black Sea water," Environmental Science and Technology, vol. 33, no. 16, pp. 2693-2702, 1999.

[16] J. L. Zhou, H. Hong, Z. Zhang, K. Maskaoui, and W. Chen, "Multi-phase distribution of organic micropollutants in Xiamen Harbour, China," Water Research, vol. 34, no. 7, pp. 2132-2150, 2000.

[17] A. El Nemr and A. M. A. Abd-Allah, "Contamination of polycyclic aromatic hydrocarbons (PAHs) in microlayer and 
subsurface waters along Alexandria coast, Egypt," Chemosphere, vol. 52, no. 10, pp. 1711-1716, 2003.

[18] J. L. Zhou and K. Maskaoui, "Distribution of polycyclic aromatic hydrocarbons in water and surface sediments from Daya Bay, China," Environmental Pollution, vol. 121, no. 2, pp. 269-281, 2003.

[19] J. J. González, L. Viñas, M. A. Franco et al., "Spatial and temporal distribution of dissolved/dispersed aromatic hydrocarbons in seawater in the area affected by the Prestige oil spill," Marine Pollution Bulletin, vol. 53, no. 5-7, pp. 250-259, 2006.

[20] A. Valavanidis, T. Vlachogianni, S. Triantafillaki, M. Dassenakis, F. Androutsos, and M. Scoullos, "Polycyclic aromatic hydrocarbons in surface seawater and in indigenous mussels (Mytilus galloprovincialis) from coastal areas of the Saronikos Gulf (Greece)," Estuarine, Coastal and Shelf Science, vol. 79, no. 4, pp. 733-739, 2008.

[21] A. M. Stortini, T. Martellini, M. Del Bubba, L. Lepri, G. Capodaglio, and A. Cincinelli, "n-Alkanes, PAHs and surfactants in the sea surface microlayer and sea water samples of the Gerlache Inlet sea (Antarctica)," Microchemical Journal, vol. 92, no. 1, pp. 37-43, 2009.

[22] Y. W. Qiu, G. Zhang, G. Q. Liu, L. L. Guo, X. D. Li, and O. Wai, "Polycyclic aromatic hydrocarbons (PAHs) in the water column and sediment core of Deep Bay, South China," Estuarine, Coastal and Shelf Science, vol. 83, no. 1, pp. 60-66, 2009.

[23] Y. L. Wu, X. H. Wang, Y. Y. Li, and H. S. Hong, "Occurrence of polycyclic aromatic hydrocarbons (PAHs) in seawater from the Western Taiwan Strait, China," Marine Pollution Bulletin, vol. 63, no. 5-12, pp. 459-463, 2011.

[24] H. Hong, L. Xu, L. Zhang, J. C. Chen, Y. S. Wong, and T. S. M. Wan, "Environmental fate and chemistry of organic pollutants in the sediment of Xiamen and Victoria harbours," Marine Pollution Bulletin, vol. 31, no. 4-12, pp. 229-236, 1995.

[25] C. D. Simpson, A. A. Mosi, W. R. Cullen, and K. J. Reimer, "Composition and distribution of polycyclic aromatic hydrocarbon contamination in surficial marine sediments from Kitimat Harbor, Canada," Science of the Total Environment, vol. 181, no. 3, pp. 265-278, 1996.

[26] P. Baumard, H. Budzinski, P. Garrigues, H. Dizer, and P. D. Hansen, "Polycyclic aromatic hydrocarbons in recent sediments and mussels (Mytilus edulis) from the Western Baltic Sea: occurrence, bioavailability and seasonal variations," Marine Environmental Research, vol. 47, no. 1, pp. 17-47, 1999.

[27] J. S. Khim, K. Kannan, D. L. Villeneuve, C. H. Koh, and J. P. Giesy, "Characterization and distribution of trace organic contaminants in sediment from Masan Bay, Korea. 1. Instrumental analysis," Environmental Science and Technology, vol. 33, no. 23, pp. 4199-4205, 1999.

[28] I. Bouloubassi, J. Fillaux, and A. Saliot, "Hydrocarbons in surface sediments from there Changjiang (Yangtze River) Estuary, East China Sea," Marine Pollution Bulletin, vol. 42, no. 12, pp. 1335-1346, 2001.

[29] M. Ma, Z. Feng, C. Guan, Y. Ma, H. Xu, and H. Li, "DDT, PAH and PCB in sediments from the intertidal zone of the Bohai Sea and the Yellow Sea," Marine Pollution Bulletin, vol. 42, no. 2, pp. 132-136, 2001.

[30] M. Notar, L. S. Hermina, and F. Jadran, "Composition, distribution and sources of polycyclic aromatic hydrocarbons in sediments of the Gulf of Trieste, Northern Adriatic Sea," Marine Pollution Bulletin, vol. 42, no. 1, pp. 36-44, 2001.

[31] S. Boitsov, H. K. B. Jensen, and J. Klungsøyr, "Natural background and anthropogenic inputs of polycyclic aromatic hydrocarbons (PAH) in sediments of South-Western Barents Sea," Marine Environmental Research, vol. 68, no. 5, pp. 236245, 2009.

[32] I. Tolosa, M. Mesa-Albernas, and C. M. Alonso-Hernandez, "Inputs and sources of hydrocarbons in sediments from Cienfuegos bay, Cuba," Marine Pollution Bulletin, vol. 58, no. 11, pp. 1624-1634, 2009.

[33] R. J. Law, V. J. Dawes, R. J. Woodhead, and P. Matthiessen, "Polycyclic aromatic hydrocarbons (PAH) in seawater around England and Wales," Marine Pollution Bulletin, vol. 34, no. 5, pp. 306-322, 1997.

[34] S. E. Jørgensen, S. N. Nielsen, and L. A. Jørgensen, Handbook of Ecological Parameters and Ecotoxicology., Elsevier, Amsterdam, The Netherlands, 1991.

[35] M. G. Barron, T. Podrabsky, S. Ogle, and R. W. Ricker, "Are aromatic hydrocarbons the primary determinant of petroleum toxicity to aquatic organisms?" Aquatic Toxicology, vol. 46, no. 3-4, pp. 253-268, 1999.

[36] W. E. Pereira, F. D. Hostettler, and J. B. Rapp, "Distributions and fate of chlorinated pesticides, biomarkers and polycyclic aromatic hydrocarbons in sediments along a contamination gradient from a point-source in San Francisco Bay, California," Marine Environmental Research, vol. 41, no. 3, pp. 299-314, 1996.

[37] R. P. Eganhouse, B. R. T. Simoneit, and I. R. Kaplan, "Extractable organic matter in urban stormwater runoff. 2. Molecular characterization," Environmental Science and Technology, vol. 15, no. 3, pp. 315-326, 1981.

[38] E. J. Hoffman, G. L. Mills, J. S. Latimer, and J. G. Quinn, "Urban runoff as a source of polycyclic aromatic hydrocarbons to coastal waters," Environmental Science and Technology, vol. 18 , no. 8, pp. 580-587, 1984.

[39] V. Dhananjayan and S. Muralidharan, "Polycyclic aromatic hydrocarbons in various species of fishes from mumbai harbour, India, and their dietary intake concentration to human," International Journal of Oceanography, vol. 2012, Article ID 645178, 6 pages, 2012.

[40] G. B. Kim, K. A. Maruya, R. F. Lee, J. H. Lee, C. H. Koh, and S. Tanabe, "Distribution and sources of polycyclic aromatic hydrocarbons in sediments from Kyeonggi Bay, Korea," Marine Pollution Bulletin, vol. 38, no. 1, pp. 7-15, 1999.

[41] E. R. Long, D. D. Macdonald, S. L. Smith, and F. D. Calder, "Incidence of adverse biological effects within ranges of chemical concentrations in marine and estuarine sediments," Environmental Management, vol. 19, no. 1, pp. 81-97, 1995. 

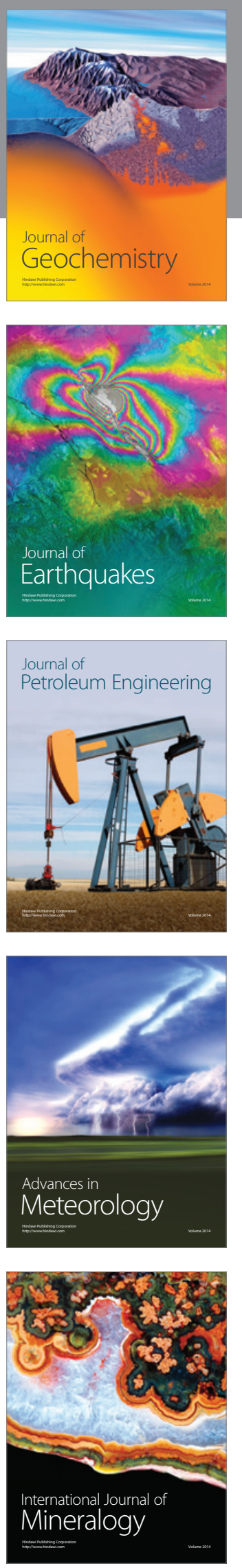
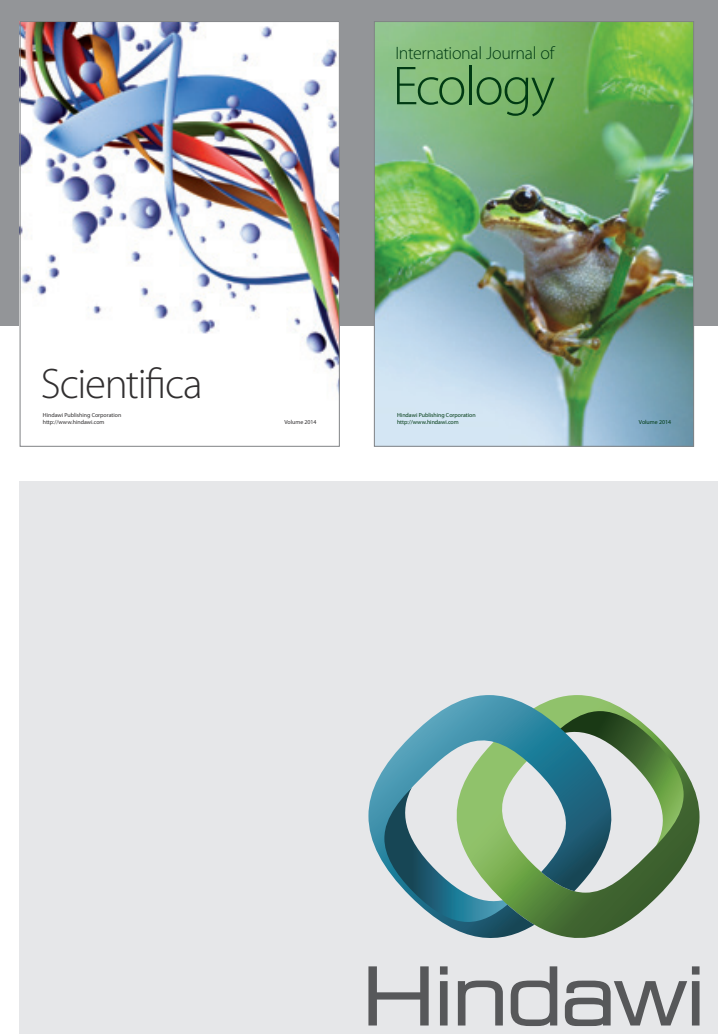

Submit your manuscripts at http://www.hindawi.com
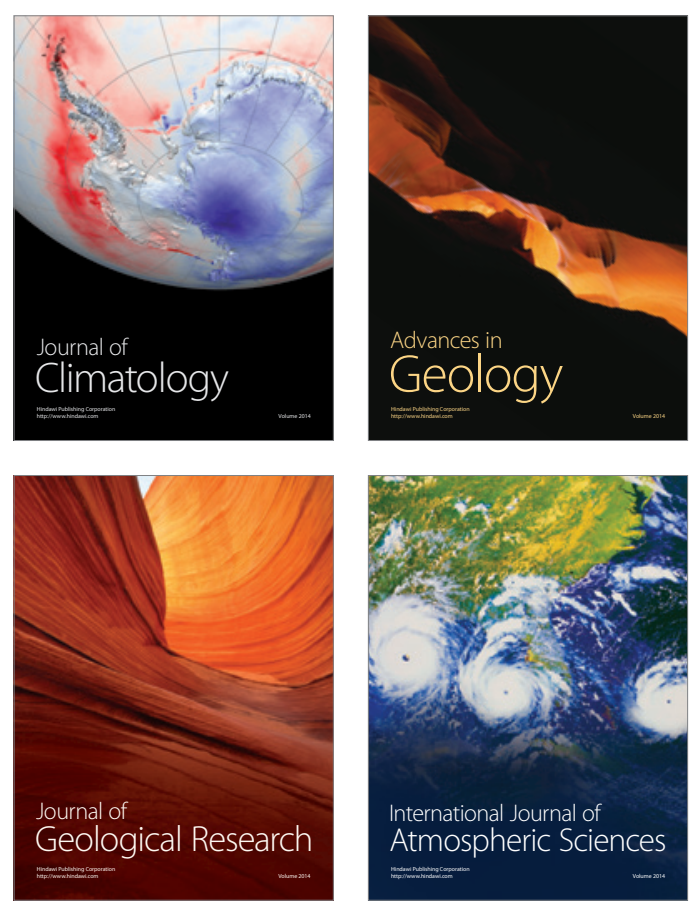
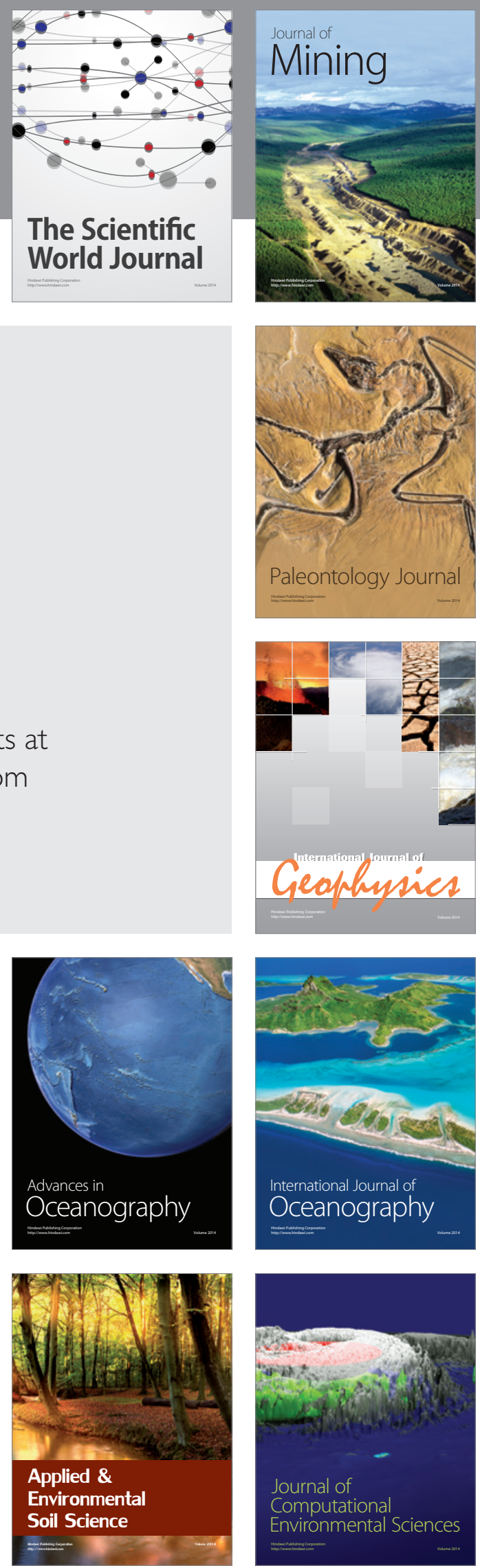